\title{
Readiness to Implement a National Quality Framework: Evidence from Irish Early Childhood Care and Education Centres
}

\author{
Orla Doyle , Caitriona Logue \& Kelly A. McNamara
}

To cite this article: Orla Doyle , Caitriona Logue \& Kelly A. McNamara (2011) Readiness to Implement a National Quality Framework: Evidence from Irish Early Childhood Care and Education Centres, Child Care in Practice, 17:2, 163-184, DOI: 10.1080/13575279.2010.546776

To link to this article: https://doi.org/10.1080/13575279.2010.546776

曲 Published online: 21 Apr 2011.

Submit your article to this journal $\pi$

Џ Article views: 394

Q View related articles $\square$

Citing articles: 2 View citing articles 4 


\title{
Readiness to Implement a National Quality Framework: Evidence from Irish Early Childhood Care and Education Centres
}

\author{
Orla Doyle, Caitriona Logue \& Kelly A. McNamara
}

This study examined the factors associated with childcare staff members' readiness to implement quality standards in early childhood settings in Ireland. To coincide with a new government policy that provides every three-year-old child with access to a free preschool year, a framework designed to improve the quality of early childhood care and education centres (ECCECs) is being rolled out nationally. The new quality framework details the first national set of best practice standards for early childhood care and education in Ireland. This study measured support for this change in childcare practices in one pilot community, which introduced the framework prior to national roll-out. The study used the Organizational Change Recipients' Belief Scale to determine how readiness for change was associated with job satisfaction and the work environment in childcare settings. One hundred and twenty surveys were completed by childcare staff in nine pilot ECCECs. The surveys were distributed in 2009 and therefore capture staff attitudes towards the introduction of the new quality framework. The results show that individual staff characteristics had little association with support for the implementation of the quality framework, while factors related to group dynamics were significantly associated with readiness for change. Specifically, a positive work environment and greater job satisfaction were associated with a lower belief that there is a need for the national quality framework, but a higher belief that the childcare staff will be supported by management when the quality framework is introduced.

\footnotetext{
Dr Orla Doyle is a Senior Researcher at the UCD Geary Institute. Caitriona Logue is a Doctoral Student at the UCD Geary Institute. Kelly A. McNamara is a Researcher at the UCD Geary Institute. Correspondence to: Caitriona Logue, UCD Geary Institute, University College Dublin, Belfield, Dublin 4, Ireland. Email: caitriona.logue@ucd.ie. This research is funded through the "Evaluation of the Preparing for Life Programme" which is conducted by the Northside Partnership and funded by Atlantic Philanthropies and the Office of the Minister for Children and Youth Affairs. Our thanks to Sandra O'Neill, the framework coordinator, and all the participating Early Childhood Care and Education Centres.
} 


\section{Introduction}

The role of early childhood care and education settings in improving children's development has begun to be viewed with increasing importance. The recognition that centre-based childcare is associated with a host of positive developmental outcomes for children, such as increased cognitive abilities, language development, and emotional and social development (Kagan \& Neuman, 1997; National Institute of Child Health and Human Development Early Childcare Research Network [NICHD], 2000, 2002, 2008; NICHD \& Duncan, 2003), has led to the introduction of a new policy in Ireland that provides every three-year-old child with access to a free preschool place for one year (Office of the Minister for Children and Youth Affairs [OMCYA], 2009). However, in order to maximise the benefit of this provision, it is important to ensure that quality childcare services are provided. Many empirical studies have highlighted this issue. For example, Peisner-Feinberg et al. (2001) find that high-quality childcare has cognitive and social benefits for all children, with stronger positive effects identified for disadvantaged children. Similarly, Vandell, Henderson, \& Wilson (1988) demonstrate that children who attend poorer-quality childcare show more problematic development and that these problems persist into later childhood.

Therefore, to ensure the effectiveness of this new preschool initiative, the participating Irish early childhood care and education centres (ECCECs) must engage in a national programme to improve childcare quality standards. This has led to the development of The National Quality Framework for Early Childhood Education (NQF). This study examined the individual and organisational factors that influence childcare staff readiness to implement the NQF in the ECCECs located in the pilot community. Examining such issues from an organisational change perspective is important, as employee resistance to new practices can slow or prevent the success of a new programme (Leiter \& Harvie, 1998). This is one of the first empirical studies to use the Organizational Change Recipients' Belief Scale (OCRBS) (Armenakis, Bernerth, Pitts, \& Walker, 2007) to measure staff readiness for change in ECCECs.

The article proceeds as follows. Details of the NQF are first described before discussing the relevance of organisational change theory. This is followed by describing the data collection procedure, the participants under examination, and the specific instruments employed. The empirical results are then reported and the implications of these results are discussed. Finally, we provide recommendations as to how staff readiness for change can be improved. These recommendations are relevant not only to Irish ECCECs, but also to other organisations implementing major workplace changes.

\section{The New National Quality Framework}

The NQF details the first national set of best practice standards for early childhood care and education in Ireland. It aims to improve the quality of ECCECs that work with children between the ages of zero and six years. Roll-out of the framework began 
in January 2010, and is now continuing across the country to coincide with the free preschool initiative. Prior to the introduction of this new initiative, the implementation of the NQF was piloted in a disadvantaged area of Ireland. The sample examined in this study comprised employees of the ECCECs located in this community. It is particularly important to focus on a disadvantaged community as the literature typically finds that high-quality childcare has the greatest returns for children from less advantaged backgrounds (Peisner-Feinberg et al., 2001).

This NQF was designed by the Centre for Early Childhood Development and Education and was launched in May 2006 by the Irish Minister for Children. The NQF was developed with the intention to define, assess, and support the quality of ECCECs (Duignan, 2005). It operates by allowing settings to reflect upon and assess the quality of service they provide to children. To this effect, the NQF aims to recognise the strengths of an ECCEC while simultaneously identifying areas in need of improvement, therefore encouraging continuous quality improvement in ECCECs.

The NQF operates under 12 interdependent principles $^{1}$ representing a comprehensive idea of quality standards in ECCECs. The 12 principles have helped inform the 16 national standards developed under the NQF, which together form a broad structure for quality in ECCECs. The 16 standards include: Rights of the Child; Environments; Parents and Families; Consultation; Interactions; Play; Curriculum; Planning and Evaluation; Health and Welfare; Organisation; Professional Practice; Communication; Transitions; Identity and Belonging; Legislation and Regulation; and Community Involvement. Each standard is broken down into several components, each having multiple areas of reflection. In total, there are 75 components in the NQF, which serve as the basis for the self-assessment of ECCECs.

There are three stages to the implementation of the NQF: registration; baseline assessment and evidence collection; and validation. First, an ECCEC must register with the NQF coordinators. This involves expressing an interest in the framework and learning about the implementation process. The second step consists of a baseline assessment, action planning, and an evidence collection period. The selfassessment is carried out with the NQF coordinator. During this process, the childcare staff are asked to reflect on the practices of their centre in relation to the 16 quality standards. To facilitate the self-assessment, these standards are broken down into open-ended questions to entice thoughtful discussion on the quality of individual and centre work. Childcare staff reflect on each of the standards, as a group, and rate the level of quality practice in their centre.

Upon completion of the baseline assessment, the centre works with the NQF coordinator to produce an action plan. This involves gathering evidence in support of the self-assessment, identifying a timeline for meeting the NQF standards, and describing the work that will take place over a fixed period of time limited to a maximum of 18 months. Once the developmental work has been carried out, ECCECs review the self-assessment tool and portfolio of evidence. At this stage, improvements relating to all $16 \mathrm{NQF}$ standards should have been completed by the centre. 
The final stage of the NQF process is validation. During this phase, the baseline self-assessment tool and portfolio are submitted and a blind, external validator reevaluates the quality level in the centre. A decision is then made as to whether or not the centre has achieved the desired level of quality outlined in the submitted portfolio. If the desired level of quality has been achieved, a quality rating valid for a two-year period is given to the centre.

The implementation of this new framework could potentially lead to a significant change of practice for some or all of the participating childcare centres. Therefore, for the purpose of this analysis, the implementation of this framework was analysed in the context of an organisational change.

\section{Relevance of Organisational Change Theory}

Organisational change is a major source of workplace stress and can be associated with a wide range of negative behavioural, psychological, and physiological outcomes including job loss, reduced status, loss of identity, interpersonal conflict, threats to self-esteem, reduced well-being, anxiety, and uncertainty (Ashford, 1988; Kanter, 1983; Martin, Jones, \& Callan, 2005; Schweiger \& Ivancevich, 1985; Terry, Callan, \& Sartori, 1996). Readiness for change can be viewed as the precursor for later support or resistance to change (Bouckenooghe \& Devos, 2007). The significance of staff acceptance of organisational change is widely recognised (for example, Gilmore \& Barnett, 1992; Sagie \& Koslowsky, 1994); therefore, it is important to understand the factors that influence staff readiness for change in order to ensure the successful implementation of the NQF. The aim of this analysis was to capture the factors that may influence employee support for the transition to the NQF in the pilot ECCECs. As Phillips, Howes, \& Whitebrook (1991) highlight, ECCEC staff are not often examined in terms of their role as adult workers; rather, the focus tends to be on their direct affect on child well-being. The authors state the importance of examining the adult work environment in order to understand the dimensions of early childcare quality and development. For this reason, it is useful to view the introduction of the NQF at a macro-level and examine it in terms of an organisational change. In the next section, contextual work factors that may influence employee acceptance of a programme for change are discussed.

\section{Contextual Factors Associated with Organisational Change}

A common finding in the organisational change literature is that job satisfaction and employees' perceptions of the work environment have an impact on staff support for a proposed transition to new work practices. In relation to job satisfaction, effective communication is key for staff morale and staff acceptance of change. For example, a retrospective study of over 3000 hospital staff whose work environment underwent significant change and restructuring found that supportive supervision, confidence in management, and effective communication were associated with a positive perception 
of change. Furthermore, confidence in management and effective communication were both directly linked to an acceptance of change (Leiter \& Harvie, 1998).

However, a certain level of dissatisfaction can also drive change. Many authors emphasise the importance of a perceived need to do things differently. So, in this sense, dissatisfaction with certain aspects of the job may entice staff to welcome change. It can be viewed as the "burning platform" (Armenakis et al., 2007, p. 484) or the antecedent of change (Taylor, Templeton, \& Baker, 2009). As Kotter (1995) explains, establishing this sense of urgency is essential because, without motivation, staff members are unlikely to support any proposed change. Thus, clear communication to staff of areas that could be improved is important. Kotter (1995, p. 60) quotes one Chief Executive Officer describing management's role as convincing staff that "the status quo is more dangerous than launching into the unknown". However, the perceived need for change is not enough in itself; beliefs related to the implementation of the proposed programme must be fostered for the organisational change to be fully supported (Armenakis et al., 2007).

The importance of the work environment also emerges as another key factor influencing the success of organisational change. One key element is effective supervision. Shipper (1991) shows that the work environment is correlated with higher morale and productivity in staff undergoing an organisational change. Walinga (2008) highlights that encouraging staff of their capability to adapt to the new practices leads to a more efficient transition. The author identifies the notion of emotionfocused coping, which arises when an individual feels overwhelmed by a challenge and, as a consequence, directs all his or her attention to controlling stress-levels. On the other hand, problem-focused coping occurs when an individual has strong self-efficacy beliefs and can direct all his or her abilities towards problem-solving.

Although supportive management plays an important role in securing employee support for a programme of change, this does not imply that staff want to play a passive role in the organisation. Sagie and Koslowsky (1994) show that greater staff involvement in tactical decision-making during planned organisational change is associated with an increased acceptance of change, work satisfaction, and perceived effectiveness of the change. The importance of staff involvement is reinforced by Rodd (1994), who finds that change is less likely to be successful when staff feel that they have little ownership of ideas in the organisation and when change is imposed from above. In other words, organisations need to examine their staff protocol from both the top-down and bottom-up in order to find the correct balance between effective supervision and employee autonomy.

In a study of organisational change in childcare nurseries, Munton, Mooney, and Rowland (1997) suggest that organisational characteristics can influence a centre's ability to change their practices. Evidence shows that environmental factors such as participatory management styles, employee involvement in decision-making, and established procedures for self assessment (Jorde-Bloom, 1995; Stephens \& Wilkinson, 1995) are often influential in the success of facilitating organisational change. Munton and Mooney (1999) summarise the empirical evidence by stating that staff are least supportive of change when they perceive their workplace as one that avoids taking risks, 
has low management support, is predominantly authoritarian, discourages participation in management decisions, has low integration, and is intolerant of conflict.

Based on the existing literature, we postulate that readiness for change in early childhood centres is primarily associated with a high level of job satisfaction and a positive/supportive work environment. However, we also propose that a certain element of dissatisfaction could serve as the "burning platform" (Armenakis et al., 2007, p. 484) to initiate initial support for the transition. Overall, we hypothesise that readiness for change is bolstered by a clear understanding of what the change will involve, a belief that the management team is supportive, and a feeling of being involved in decision-making.

\section{Method}

\section{Procedure}

Prior to the national roll-out, the NQF is currently in the pilot stage. As part of the evaluation of the NQF implementation process, a study assessing readiness to implement the NQF among centres in the pilot community was developed. Questionnaires assessing basic demographics, knowledge of the NQF, readiness for the organisational change, job satisfaction, and the work environment were administered to all childcare staff working in ECCECs participating in the NQF pilot study between February and June 2009. The management in the ECCECs distributed the paper-and-pencil questionnaire, which was self-completed by centre staff. Upon completion of the questionnaire, staff sealed the questionnaire in a selfaddressed, stamped envelope to be directly returned to the research team. Questionnaires were distributed after each childcare centre had registered to adopt the new standards, but before the staff began implementing the NQF.

\section{Participants}

In total 136 surveys were distributed across nine childcare centres, and 120 surveys were completed resulting in a response rate of $88.24 \%$. These centres serve children between zero and five years of age. Forty-four per cent of the centres are entirely state run, while $56 \%$ operate on a combination of state funding and child fees; thus there are no fully private centres operating in this area. All nine centres are regulated by a government agency. As this organisational change is related to early childhood carers, job descriptions that did not involve direct involvement with child education and care on a regular basis $(n=16$; e.g., bus driver, kitchen staff, receptionist) were excluded from the analyses. Therefore, the results reported below are based on the responses of 104 respondents (76.37\%).

The survey contained several questions related to the demographics of centre staff, their time spent working in the centre, and their professional role. Overall, $38 \%$ of respondents work more than 35 hours per week in the centre, $44 \%$ work between 20 and 35 hours per week, and 18\% of respondents are employed part-time, working between 10 and 19 hours per week. The average age of respondents was 37 (standard deviation 
$[S D]=10.55)$ years, with a range of 20-64 years of age. All respondents, bar one, were female. On average, respondents had been working in the field of early childhood care and education for eight years $(S D=7.23)$, had been in their current centre for five years $(\mathrm{SD}=4.35)$, and in their current role at the centre for four years $(\mathrm{SD}=5.03)$.

In terms of education, $45 \%$ of respondents had the Junior Certificate (Irish state examinations taken after three years in secondary school). Additionally, 6\% dropped out before completing secondary school, $10 \%$ had the Leaving Certificate (the Irish equivalent of A-levels), and $26 \%$ had a non-degree qualification, $10 \%$ had a primary degree, and $3 \%$ had a postgraduate qualification.

\section{Instruments}

The primary part of the study was developed and conducted under the theoretical framework of Readiness for Change (Armenakis, Harris, \& Mossholder, 1993). Two instruments were employed to examine staff members' knowledge of the NQF and their expectation of how successful their centre would be at implementing it. Standardised measures were then used to assess readiness for change and the factors related to organisational change such as work environment and job satisfaction. Underlying descriptions of each of these instruments is described in detail below.

\section{Knowledge of NQF and perceptions of success}

Staff members were asked to assess their knowledge of the NQF on a five-point scale ranging from "I do not know anything" to knowing "a large amount of information" about the NQF. Respondents were also asked to predict how successful their centre would be at implementing the change by answering "yes", "no", or "don't know" to the question "Do you think your centre will be successful at reaching the NQF standards?"

\section{Readiness for change}

Readiness for change (i.e. readiness to implement the NQF) was assessed using the OCRBS (Armenakis et al., 2007). Respondents were asked to rate how much they agree or disagree with each statement on a seven-point Likert scale ranging from "strongly disagree" to "strongly agree". This scale provides scores in five domains: discrepancy (four items; $\alpha=0.87$ ) refers to employees' beliefs on whether the need for change is present in the centre, appropriateness (five items; $\alpha=0.87$ ) measures whether the proposed change addresses the needs of the centre, efficacy (five items; $\alpha=0.83$ ) represents the capacity of the organisation to implement the change, principal support (six items, $\alpha=0.80$ ) refers to the effectiveness of management in the centre, and valence (four items, $\alpha=0.63$ ) is defined as the appeal of the perceived benefit of the change. The OCRBS also yields an overall readiness for change score (24 items, $\alpha=0.91$ ), which represents the respondent's overall readiness for the proposed change and is an average of all domains described above. 
One observation was excluded from the analyses because more than $50 \%$ of data was missing for this respondent. Scores for each domain range from one to seven and represent the mean of responses for that category. Higher scores are indicative of a stronger belief that the centre is ready for the implementation of the NQF.

\section{Work environment}

The work environment operating at the centre was assessed using the Organisational Climate section of the Early Childhood Work Environment Survey (Jorde-Bloom, 1996). This is a measure of childcare centre employees' feelings about their work surroundings. Respondents were asked to select a number of items that characterise their centre. This instrument provides scores related to collegiality, professional growth, supervisor support, clarity, decision-making, goal consensus, task orientation, physical setting, and innovativeness within the centre. Scores are reported on a scale of zero to 10, with higher scores representing a more positive organisational climate.

This instrument also assessed the amount of influence staff had compared with the level of influence that they desired in the domains of ordering materials, interviewing, programme objectives, training, and planning. The total scores for these categories range from zero to 10, with higher numbers representing a greater amount of influence. In order to analyse the relationship between employee influence and readiness for change, the difference between the current influence rating and the desired influence rating was calculated for each of the categories. The average of these five measures was also generated to gauge the overall disparity for each respondent.

\section{Job satisfaction}

Global job satisfaction of centre staff was measured using the following question: "On the whole, how satisfied would you say you are with your current job?" Responses were provided on a seven-point Likert scale ranging from "very dissatisfied" to "very satisfied."

The Job Satisfaction Scale (Andrews \& Withey, 1976) was used to assess employee satisfaction with several specific components of the job. The instrument consists of five items in which the respondent rates his or her happiness in relation to aspects of his or her job including: the job itself, the colleagues, the work the respondent does on the job, the employment setting, and available resources. Respondents rate these items on a scale ranging from "terrible" to "delighted". All scores related to job satisfaction are presented on a scale of one to seven, with higher scores illustrating higher job satisfaction.

\section{Results}

\section{Knowledge of the NQF and Perceptions of Success}

On average, centre staff felt that they knew "a little bit" about the NQF as reflected in the mean score of three out of five, as illustrated in Table 1. More specifically, 2\% of 
participants indicated that they did not know anything about the NQF, 25\% said they did not know very much about it, $41 \%$ stated that they knew a little bit, $26 \%$ felt they knew a moderate amount, and finally 5\% indicated that they knew a large amount about the NQF. As regards the perception of success, the majority (89\%) of staff indicated that their centre would be successful at meeting the new standards, with only one respondent expressing a belief that they would not be successful; while 10 respondents indicated that they were unsure of whether they would be successful or not. Unlike all the measures used in the analysis, due to a lack of variation in responses to the perception of success question, this variable could not be tested for correlations with the OCRBS domains.

Table 1 Key Instruments

\begin{tabular}{|c|c|c|c|c|c|}
\hline Variable & $N$ & Mean & $\begin{array}{l}\text { Standard } \\
\text { deviation }\end{array}$ & Minimum & Maximum \\
\hline \multicolumn{6}{|l|}{ Knowledge of change } \\
\hline NQF knowledge & 99 & 3.07 & 0.90 & 1.00 & 5.00 \\
\hline \multicolumn{6}{|l|}{$O C R B S$} \\
\hline Discrepancy & 103 & 5.28 & 1.21 & 2.00 & 7.00 \\
\hline Appropriateness & 103 & 5.99 & 0.82 & 2.25 & 7.00 \\
\hline Efficacy & 103 & 6.18 & 0.62 & 4.00 & 7.00 \\
\hline Principal support & 103 & 5.86 & 0.83 & 2.67 & 7.00 \\
\hline Valence & 103 & 4.93 & 0.89 & 1.50 & 7.00 \\
\hline Overall OCRBS & 103 & 5.70 & 0.61 & 3.79 & 6.87 \\
\hline \multicolumn{6}{|l|}{ Work environment } \\
\hline Collegiality & 104 & 7.51 & 2.29 & 0 & 10 \\
\hline Professional growth & 104 & 5.14 & 2.67 & 0 & 10 \\
\hline Supervisor support & 104 & 7.49 & 2.00 & 0 & 10 \\
\hline Clarity & 104 & 5.94 & 2.59 & 0 & 10 \\
\hline Decision-making & 104 & 6.52 & 2.19 & 0 & 10 \\
\hline Goal consensus & 104 & 7.24 & 2.31 & 2 & 10 \\
\hline Task orientation & 104 & 7.44 & 2.09 & 1 & 10 \\
\hline Physical setting & 104 & 6.79 & 2.44 & 1 & 10 \\
\hline Innovativeness & 104 & 7.07 & 1.92 & 2 & 10 \\
\hline \multicolumn{6}{|l|}{ Influence disparity } \\
\hline Ordering materials & 98 & 2.55 & 4.20 & -10 & 10 \\
\hline Interviewing & 89 & 2.42 & 3.46 & -10 & 10 \\
\hline Program objectives & 79 & 2.22 & 3.65 & -10 & 10 \\
\hline Training & 90 & 1.11 & 4.02 & -10 & 10 \\
\hline Planning & 99 & 0.40 & 2.83 & -10 & 10 \\
\hline Overall disparity & 75 & 1.77 & 2.33 & -4 & 8 \\
\hline \multicolumn{6}{|l|}{ Job satisfaction } \\
\hline Global satisfaction & 97 & 6.28 & 0.93 & 2 & 7 \\
\hline Job & 103 & 6.18 & 1.02 & 4 & 7 \\
\hline Colleagues & 103 & 6.28 & 0.93 & 3 & 7 \\
\hline Work & 103 & 6.30 & 0.70 & 4 & 7 \\
\hline Employment setting & 102 & 5.90 & 1.01 & 2 & 7 \\
\hline Available resources & 102 & 5.77 & 1.23 & 1 & 7 \\
\hline
\end{tabular}




\section{Readiness for Change ${ }^{2}$}

Table 1 reports the mean readiness for change scores in each of the five OCRBS domains. The efficacy domain received the highest rating, while the lowest score was in the valence domain. Scores were high across all domains and overall readiness for change was rated 5.7 out of seven, suggesting that on the whole, staff feel they are ready for the transition.

\section{Work Environment}

Mean ratings for each of the nine work environment domains are presented in Table 1. Overall, staff in the ECCECs rated all categories positively, with mean scores ranging between 5.1 and 7.5. Collegiality and supervisor support received the highest scores, while professional growth received the lowest.

Figure 1 compares the respondents' current level of influence to their desired level of influence. These values represent the averages for all respondents. As demonstrated, significance tests ${ }^{3}$ reveal that staff members wish to be more involved in ordering materials $(z=-5.49, p<0.001)$, interviewing potential staff members $(z=-5.76, p<0.001)$, determining programme objectives $(t(78)=-5.40, p<0.001)$, and training opportunities $(z=-2.64, p<0.01)$. A difference between staff members' current and desired influence in the domain of planning was observed at the trend level $(z=-1.67, p<0.10)$.

The mean values for the influence disparity measures, presented in Table 1, are consistent with these results. On average, the difference between current and desired influence was positive for all categories. The magnitude of the difference was highest for ordering materials (2.55) and lowest for planning (0.40).

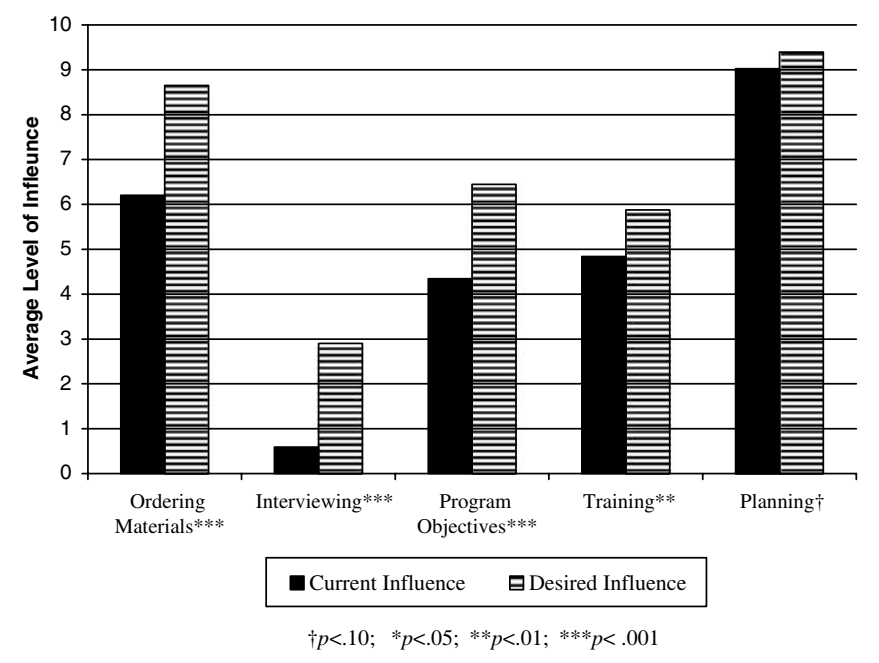

Figure 1 Current and Desired Influence in Decision-making.

Note: This figure illustrates the difference between staff members' current and desired influence in various aspects of the organisation. 


\section{Job Satisfaction}

Mean job satisfaction ratings are reported in Table 1. All scores were high, and ranged between 5.77 and 6.3. Furthermore, global job satisfaction received a mean score of 6.28 , which lies between the "satisfied" and "very satisfied" response options.

In terms of more specific aspects of job satisfaction, respondents felt happiest with their work, their colleagues, and the job itself. Although the employment setting and available resources were rated lowest, the mean scores were still high and indicative of a "mostly satisfied" response.

\section{Relationship between OCRBS, Individual Characteristics, Work Environment, Job Satisfaction and Employee Influence}

Organisational change theory suggests that readiness for change may be influenced by the work environment and staff job satisfaction. Spearman Rho non-parametric correlation testing was applied to examine relationships between each OCRBS domain and individual characteristics, work environment, and job satisfaction. The possibility of examining the correlation between hours worked and readiness for change was postulated. However, the Mann-Whitney rank sum test was used to compare readiness for change among full-time and part-time workers and no statistical differences were found on any of the readiness for change domains. ${ }^{4}$ Therefore, this avenue was not explored any further. Correlation coefficients presented in Table 2 show that the majority of individual staff characteristics were not associated with readiness for change. However, several significant associations emerged between the OCRBS domains and factors related to job satisfaction and the centre itself. It is important to note, however, that although several significant relationships emerged, the magnitude of such correlation coefficients is small (between 0.16 and 0.45 ).

\section{OCRBS: discrepancy}

No significant relationships emerged between the OCRBS discrepancy belief domain and individual characteristics of staff. However, there was a negative correlation between discrepancy and seven of the nine work environment categories. Specifically, there were negative relationships between the OCRBS discrepancy domain and collegiality $(r=-0.36, p<0.001)$, supervisor support $(r=-0.25, p<0.01)$, decision making $(r=-0.20, p<0.05)$, goal consensus $(r=-0.32, p<0.01)$, task orientation $(r=-0.44, p<0.001)$, physical setting $(r=-0.38, p<0.001)$, and innovativeness $(r=-0.39, p<0.001)$.

The discrepancy domain was positively related to variables measuring the disparity between current and desired level of influence. Results indicate that staff who desired more influence in ordering materials $(r=0.28, p<0.01)$ and programme objectives $(r=0.42, p<0.001)$ had a stronger belief that a change is needed. Furthermore, overall disparity was positively and significantly correlated with the discrepancy belief $(r=0.32, p<0.01)$. 
Table 2 Correlation Coefficients between OCRBS Scales and Individual Characteristics, Work Environment Factors, and Job Satisfaction

\begin{tabular}{|c|c|c|c|c|c|c|}
\hline & Discrepancy & Appropriateness & Efficacy & $\begin{array}{l}\text { Principal } \\
\text { support }\end{array}$ & Valence & Overall \\
\hline \multicolumn{7}{|c|}{ Individual characteristics } \\
\hline Age & -0.03 & 0.11 & 0.14 & 0.08 & 0.05 & 0.09 \\
\hline Education & 0.00 & -0.13 & 0.04 & -0.16 & $-0.25^{\star}$ & -0.14 \\
\hline $\begin{array}{l}\text { Years in early } \\
\text { childhood }\end{array}$ & 0.09 & -0.04 & 0.03 & -0.16 & -0.05 & -0.03 \\
\hline Years in centre & 0.07 & 0.02 & 0.11 & -0.10 & -0.07 & 0.02 \\
\hline $\begin{array}{l}\text { Years in current } \\
\text { role }\end{array}$ & 0.04 & 0.04 & 0.13 & -0.16 & -0.06 & -0.02 \\
\hline NQF knowledge & 0.14 & 0.19 & $0.24^{\star}$ & 0.02 & 0.08 & 0.13 \\
\hline \multicolumn{7}{|c|}{ Work environment factors } \\
\hline Collegiality & $-0.36^{* * *}$ & 0.02 & 0.14 & $0.22^{\star}$ & -0.07 & -0.02 \\
\hline $\begin{array}{l}\text { Professional } \\
\text { growth }\end{array}$ & -0.10 & $0.20^{*}$ & $0.20^{\star}$ & $0.40^{* * *}$ & 0.02 & 0.18 \\
\hline $\begin{array}{l}\text { Supervisor } \\
\text { support }\end{array}$ & $-0.25^{\star *}$ & 0.08 & 0.12 & $0.43^{\star * *}$ & 0.13 & 0.12 \\
\hline Clarity & -0.16 & 0.13 & $0.22^{\star}$ & $0.33^{* * *}$ & 0.17 & 0.14 \\
\hline $\begin{array}{l}\text { Decision- } \\
\text { making }\end{array}$ & $-0.20^{\star}$ & 0.08 & 0.18 & $0.40^{\star * *}$ & 0.15 & 0.16 \\
\hline Goal consensus & $-0.32^{\star *}$ & 0.06 & 0.18 & $0.39^{* * *}$ & 0.02 & 0.08 \\
\hline Task orientation & $-0.44^{* * *}$ & -0.03 & -0.01 & $0.31^{* *}$ & -0.10 & -0.06 \\
\hline Physical setting & $-0.38^{\star * *}$ & 0.00 & 0.07 & $0.24^{*}$ & 0.02 & -0.04 \\
\hline Innovativeness & $-0.39^{* * *}$ & 0.03 & 0.16 & $0.27^{\star \star}$ & $-0.21^{\star}$ & -0.04 \\
\hline \multicolumn{7}{|c|}{ Desired - current influence } \\
\hline $\begin{array}{l}\text { Overall } \\
\text { difference }\end{array}$ & $0.32^{\star *}$ & 0.10 & 0.13 & $-0.25^{\star}$ & 0.02 & 0.10 \\
\hline $\begin{array}{l}\text { Ordering } \\
\text { materials }\end{array}$ & $0.28^{\star *}$ & 0.00 & -0.03 & $-0.32^{\star *}$ & -0.05 & -0.01 \\
\hline Interviewing & 0.05 & -0.05 & 0.08 & -0.11 & -0.03 & -0.06 \\
\hline $\begin{array}{l}\text { Program } \\
\text { objectives }\end{array}$ & $0.42^{\star * *}$ & 0.10 & 0.10 & -0.14 & 0.02 & 0.18 \\
\hline Training & 0.17 & 0.04 & 0.05 & -0.10 & -0.01 & 0.04 \\
\hline Planning & 0.17 & 0.06 & -0.01 & $-0.21^{\star}$ & 0.07 & 0.00 \\
\hline \multicolumn{7}{|l|}{ Job satisfaction } \\
\hline $\begin{array}{l}\text { Global } \\
\text { satisfaction }\end{array}$ & $-0.24^{\star}$ & 0.18 & 0.09 & $0.36^{\star * *}$ & 0.07 & 0.14 \\
\hline Job & -0.04 & $0.29^{\star *}$ & $0.25^{\star}$ & $0.34^{\star * *}$ & $0.34^{\star * *}$ & $0.33^{\star * *}$ \\
\hline Colleagues & -0.10 & 0.12 & $0.20^{\star}$ & $0.27^{\star \star}$ & 0.07 & 0.17 \\
\hline Work & 0.03 & $0.32^{\star \star}$ & $0.36^{\star * *}$ & $0.25^{\star}$ & $0.22^{\star}$ & $0.30^{\star \star}$ \\
\hline $\begin{array}{l}\text { Employment } \\
\text { setting }\end{array}$ & -0.17 & 0.19 & 0.15 & $0.45^{\star * *}$ & 0.07 & 0.18 \\
\hline $\begin{array}{l}\text { Available } \\
\text { resources }\end{array}$ & -0.18 & 0.15 & 0.15 & $0.43^{* * *}$ & $0.20^{*}$ & $0.20^{\star}$ \\
\hline
\end{tabular}

${ }^{\star} p<0.05 .{ }^{* *} p<0.01 .{ }^{* *} p<0.001$.

An inverse relationship emerged between the OCRBS discrepancy domain and global job satisfaction $(r=0.24, p<0.05)$, indicating that staff who were satisfied with their job were less likely to believe that a change was needed in their centre. 


\section{OCRBS: appropriateness}

The perceived appropriateness of the NQF was not significantly associated with any of the individual staff characteristics.

In terms of the work environment, one significant relationship emerged with the OCRBS appropriateness domain. Perceived appropriateness of the change was positively associated with professional growth $(r=0.20, p<0.05)$. No significant associations with the influence disparity measures were found.

Two categories related to job satisfaction were positively associated with appropriateness: satisfaction with the job itself $(r=0.29, p<0.01)$ and the work one does on the job $(r=0.32, p<0.01)$.

\section{OCRBS: efficacy}

Similar to the previous OCRBS domains, the relationship between individual characteristics of early childcare staff and the OCRBS efficacy belief was not statistically significant. A positive relationship was identified between the respondents' level of knowledge about the NQF and their confidence that the change could be implemented successfully $(r=0.24, p<0.05)$.

There was also evidence that self-rated efficacy was related to work-specific factors. Results show that those who were happy with their work environment anticipated that their centre would undergo the transition successfully. Specifically, professional growth $(r=0.20, p<0.05)$ and clarity $(r=0.22, p<0.05)$ were significantly related to the OCRBS efficacy domain.

With respect to employees' involvement in workplace decisions, the disparity between current and desired level of influence was not significantly correlated with staff confidence in their centre's ability to make a successful transition.

Job satisfaction was associated with higher perceptions of efficacy. The results indicate that those who were happier with their current job $(r=0.25, p<0.05)$, their colleagues $(r=0.20, p<0.05)$, and the work they do on their job $(r=0.36, p<0.001)$ had a stronger belief that the organisational change can be successfully implemented in their centre.

\section{OCRBS: principal support}

Following a similar pattern to the other OCRBS domains, no significant correlations were found between individual characteristics and the OCRBS category of principal support. However, all work environment factors were positively correlated with the principal support measure. Specifically the association was precisely determined for collegiality $(r=0.22, p<0.05)$, professional growth $(r=0.40, p<0.001)$, supervisor support $(r=0.43, p<0.001)$, clarity $(r=0.33, p<0.001)$, decision-making $(r=0.40$, $p<0.001)$, goal consensus $(r=0.39, p<0.001)$, task orientation $(r=0.31, p<0.01)$, physical setting $(r=0.24, p<0.05)$, and innovativeness $(r=0.27, p<0.01)$.

Three of the influence disparity measures were negatively and significantly associated with principal support. Specifically, those who desired more influence in 
the ordering of materials $(r=-0.32, p<0.01)$ and planning aspects of the centre $(r=-0.21, p<0.05)$ had less confidence in management supportiveness. The overall disparity $(r=-0.25, p<0.05)$ measure was also negatively correlated with the principal support belief domain.

All of the job satisfaction measures were positively correlated with the principal support measure. The more satisfied staff were with their job $(r=0.34, p<0.001)$, their colleagues $(r=0.27, p<0.01)$, the work they do on the job $(r=0.25, p<0.05)$, the employment setting $(r=0.45, p<0.001)$, and the available resources in the centre $(r=0.43, p<0.001)$, the higher they rated the support they receive from management in the ECCEC.

\section{OCRBS: valence}

The OCRBS valence domain was negatively correlated with the respondents' level of education $(r=-0.25, p<0.05)$.

In terms of the work environment factors, a negative relationship was found between innovativeness and the OCRBS valence domain $(r=-0.21, p<0.05)$. The valence domain was positively related to respondents' satisfaction with the job itself $(r=0.34, p<0.001)$, the work $(r=0.22, p<0.05)$ and the available resources on the job $(r=0.20, p<0.05)$, indicating that staff who are satisfied in their job are more likely to believe that there will be positive outcomes associated with the introduction of the NQF.

\section{OCRBS: overall readiness for change}

The results from the correlation analysis indicate that overall readiness for change was not associated with any of the staff demographic characteristics. Neither was it correlated with the work environment or the influence disparity measures.

On the other hand, three of the job satisfaction categories were positively and significantly related to overall readiness for change. Specifically, they were: the job itself $(r=0.33, p<0.001)$, the work the respondent does on the job $(r=0.30$, $p<0.01)$, and the available resources in the workplace $(r=0.20, p<0.05)$. Together, these findings suggest that the more satisfied employees are with aspects of their job, the more supportive they are of the proposed programme of change.

\section{Discussion}

This study examined the factors associated with childcare staff members' readiness to implement quality standards in ECCECs that were all, at least partly, governmentfunded. As all ECCECs were operating in designated disadvantaged areas, thus the high reliance on government funding was typical of such areas. Overall staff members in the ECCECs appeared happy with their current careers and the proposed implementation of the NQF. They rated all aspects of their work environment highly and conveyed high satisfaction with their roles in the centre. Yet, there was room for 
improvement in relation to how well-informed staff members were about the NQF and the level of responsibility they were granted. Specifically, the results show that, on average, staff indicated that they knew only "a little bit" about the NQF, and staff also indicated that they would like to have more influence in decision-making made within their centre. Nevertheless, the majority of childcare staff rated themselves as ready to implement the NQF to some extent, while correlation analysis revealed that the strength of their belief was related to centre-specific factors such as collegiality, innovativeness and job satisfaction.

\section{Individual Characteristics}

Previous studies assessing readiness for change in schools found that teachers felt that the change had to be embraced by the organisation as a whole rather than the individual in order to be successful (Walsh \& Gardner, 2006), which suggests that individual characteristics may be less important than group or centre characteristics throughout the process of an organisational change. The findings from this study reinforce this theory. Overall, staff members' individual characteristics had little impact on readiness for organisational change. There was one exception: a negative correlation was found between the educational level of the staff and the OCRBS valence belief domain, suggesting that respondents with more formal academic qualifications perceived the outcome associated with the NQF to be less attractive than those with fewer formal qualifications. One plausible explanation for this is that many items within this domain are particularly focused on the individual (i.e. "This change will benefit me", "I will earn higher pay from my job after this change"). The focus is on the benefit for the individual rather than the rewards for the centre as a whole. Those with fewer formal qualifications may have felt that the experience of working under a recognised national framework could enhance their careers; while those with well-established qualifications already had a means by which to signal their ability to employers. Each of the other readiness for change domains, however, focus on the centre rather than the individual, which may explain the lack of highly significant relationships between individual characteristics and the OCRBS discrepancy, appropriateness, principal support, efficacy, and overall readiness for change domains.

\section{Knowledge of the NQF}

It is important to note that the survey was administered after the ECCEC had indicated they wanted to participate in the NQF, but before the developmental work associated with the framework began. Therefore, due to the timing of the survey, it is not surprising that few staff members indicated that they knew a great deal about the framework.

Although the childcare staff did not indicate a high level of knowledge about the NQF, surprisingly the vast majority $(89 \%)$ of them indicated that their centre would be successful at making the transition to the NQF, as measured using the perception 
of success instrument. This result was consistent with the strong sense of readiness for change that was determined using the OCRBS instrument. The correlation results echo the surprising finding that knowledge of the framework was not associated with overall readiness for change. However, the strength of belief in the efficacy domain was associated with greater awareness of the NQF. Perhaps being more informed about the change may allow staff to feel they are capable of adapting to it. When staff members know little about what to expect in the transition process, the idea of "meeting new standards" may appear more daunting. Ensuring that staff are informed of the upcoming change and reasons for the change may prove beneficial for the uptake and implementation of the framework at a national level. Other research, in which focus group methods were used, found that although teachers may agree with a proposed change, they often feel they have minimal resources and not enough training to be fully ready for it (Walsh \& Gardner, 2006). Therefore, it is important to inform staff of what the transition to the NQF will involve and bolster confidence that management will be supportive throughout the change.

\section{Work Environment and Job Satisfaction}

Several small to moderately significant correlations emerged between the readiness for change domains and work-specific factors. Two definite patterns were identified, including a negative correlation between the OCRBS discrepancy domain and working conditions, and positive associations between the OCRBS principal support domain and work-specific variables. Staff who rated their work environment positively and those who were satisfied in their jobs were less likely to believe that there was a need for the NQF in their centre. However, they also had a stronger belief that they would be supported by the management during the transition process. This negative correlation between the belief that change is needed and job satisfaction rejects the idea that positive feelings about work are associated with higher scores across all readiness for change domains. Indeed, in line with our central hypothesis, we found the opposite was true with respect to employees' belief in the necessity for change.

The results imply that although there was, on average, a strong belief that a discrepancy, or a need for change existed, this sense of urgency actually decreased with improved working conditions and job satisfaction. Conversely, it increased when staff desired more influence in the running of their centre. A possible explanation for this is that negative sentiments could be attached to some of the discrepancy domain items, such as "we need to improve the way we operate in this organisation". Those who enjoyed their work and those who were content with their positions were less likely to agree with such statements. Similarly, employees believed, on average, that management would be supportive during the transition process; however the strength of this belief was positively correlated with all work environment and job satisfaction measures. Also, the belief that management would be supportive of the change decreased when there was a greater disparity between staff's desired and current influence in centre decisions. This reinforces the evidence from other studies that 
show successful transitions are more likely to occur in organisations that adopt bottom-up approaches which encourage staff participation (Rodd, 1994; Sagie \& Koslowsky, 1994).

For the OCRBS appropriateness, efficacy, and valence belief domains, the significant relationships were more varied. All of the significant correlation coefficients in the work environment and job satisfaction categories were positively associated with these OCRBS belief domains, with one exception in relation to innovativeness, which is discussed later. These positive correlations correspond to the existing theory that support for organisational change increases with management support and effective communication (Leiter \& Harvie, 1998; Shipper, 1991; Walinga, 2008).

Although the need for change was more apparent in ECCECs where workers felt less satisfied, the results suggest that support for the implementation of change was associated with employees that were happy in their jobs. The results point towards the possibility that staff members who felt that the NQF was unnecessary in their centre may have been happy, at the same time, with the transition proposed and felt that they would have adequate support throughout the change process.

Yet, surprisingly, the results indicate that work environment factors and influence disparity measures had no significant impact on overall readiness for change, despite these factors being strongly associated with specific OCRBS domains. It appears that overall support for the change was neutralised by the opposing negative and positive forces between the belief that change was needed and the belief that management would facilitate a smooth transition if the change actually occurred. Therefore, it is important for centre management to focus on conveying the message of why a change is needed in centres where staff are content. Armenakis et al. (2007) highlight the importance of the discrepancy belief and say it is the foundation necessary to motivate staff to support the transition. The analysis in this study suggests that it may be more accurate to consider it a complimentary idea; it should be examined in conjunction with the other OCRBS belief domains in order to truly understand a centre's readiness for change.

Surprisingly, a negative relationship was found between innovativeness and the valence domain of the OCRBS. This result suggests that staff who felt that they were encouraged to be creative in their work believed a less appealing outcome would result from implementing the NQF. It is possible that staff were worried that a more rigid framework would stifle their freedom to develop ideas of their own.

\section{Limitations of the Study}

While several interesting findings related to perceptions and beliefs about the implementation of the NQF emerged from this study, several limitations were present. First, the small nature of the sample had implications as regards the statistical analysis. Traditional statistical methods, such as linear regression, work under the assumption of large sample sizes, and therefore the analyses in this study were limited to examining correlations or associations in the data. They are indicative 
of underlying relationships that may exist between two factors; however, they are not necessarily causal relationships, nor should they be interpreted as such. An additional constraint associated with the small sample size was reduced variation in the responses recorded for each question. This, in turn, made it more difficult to find definite trends in the data. Also, within-centre analysis was not possible as separating the results for each ECCEC would have made them potentially identifiable, thus breaching confidentiality. Given the varying number of staff working at each centre, all analyses were conducted with and without using frequency weights. As there were no major differences across both sets of results, the unweighted analyses are presented here.

Another potential limitation is the issue of common method variance. Common method variance occurs when the dependent and independent variables are derived from the same respondent. Thus, it is possible that shared variance may have occurred in these analyses as the respondents provided data on all variables used. Another limitation is that this study was conducted at a single point in time and thus does not examine the outcomes associated with the implementation of the NQF.

As this study focused on readiness for change, the survey was conducted prior to the implementation of the change. Thus, the staff's knowledge of the NQF was more limited than if the survey was conducted during the implementation phase. Specifically, 25\% of staff indicated that they did not know much about the NQF. The limited knowledge of the NQF in participating ECCECs may be viewed as a limitation of the present work. Although the sample size in this study does not allow the researchers to analyse this, future work in this area may benefit from examining these relationships among staff who know a large amount about the NQF and those who do not know a great deal about the framework.

Also, it should be noted that this study explored staff readiness to adopt the NQF in one disadvantaged Irish community, during the pilot phase. The framework that is eventually implemented across Ireland, as part of the national roll-out, could differ from the pilot programme. Also, staff attitudes in other areas of Ireland could differ significantly from those working in a disadvantaged community.

\section{Conclusion}

The NQF is the first nationally agreed upon set of quality standards for early childcare and education settings in Ireland. The goal of this framework is to improve the standard of early childcare for children aged zero to six. By identifying factors that are correlated with the successful adoption of the NQF, it is hoped that policy workers and management in the ECCECs will be aware of ways to ease the transition process in the future. This has the potential to increase the success of the NQF rollout across Ireland and, indeed, the potential to improve our understanding of organisational change in early childhood settings.

This study examined staff readiness to implement the NQF in ECCECs taking part in the pilot programme. Given that the study was conducted in a disadvantaged community, the results are particularly relevant as research shows that high-quality 
childcare is most beneficial for children from low-income backgrounds with a high risk of family adversity (Peisner-Feinberg et al., 2001). The implementation of the $\mathrm{NQF}$ in the local early childhood settings may, therefore, have important long-term consequences if implemented with fidelity.

As the successful implementation of the framework is dependent on the readiness of the staff to engage and support the change, this study sought to identify the factors that may be correlated with readiness for change, such as individual staff characteristics, the work environment and the level of job satisfaction experienced by the staff working at ECCECs. Thus, providing insight into the policies that ensure the successful implementation of the NQF will result in higher-quality preschool care and education centres in Ireland. Given that the Irish government has recently introduced a new initiative that provides parents with the option of a free preschool year for three-year-old children (OMCYA, 2009), the importance of childcare quality is particularly relevant. Parental utilisation of this new policy could increase if the rollout of the NQF is successful, and the take-up of the NQF depends on childcare workers' readiness to adopt it. The results may also hold relevance for other forms of organisations undergoing large workplace changes and contribute to the general literature on readiness for change.

The results highlight the importance of effective communication. Staff with a greater knowledge of the NQF had more positive beliefs that the centre had the capacity to implement the change. A clear means to improving staff readiness for change is therefore to simply inform staff of what the change will involve as launching into an unknown process is a much more daunting task and, hence, may cause more confusion and distraction (Walinga, 2008).

It is also important to communicate to staff that a change aimed at improving the quality of childcare will not have an adverse effect on their working conditions. The results indicate that staff who are happy in their work environment are less likely to recognise a need for change. This may be due to what Cameron (2008) refers to as the paradox of positive change. He describes the paradox thus: although humans are drawn to positive rather than negative situations, they react more strongly to negative stimuli. Therefore, if the managers and those implementing the NQF highlight some of the faults in the current system, staff may be more inclined to support the transition.

Another key implication of the implementation of the NQF is that it may have differing effects on staff depending on their level of education. The results indicate that employees with fewer formal qualifications anticipate more potential benefits from adapting to the new framework. As we do not find that education is associated with any of the other domains, outside valence, it is possible that education may have stronger associations with readiness for change and that a lack of variation in this sample prevented us from identifying more effects. The relationship between valence and education is interesting in itself, and leads us to recommend that, prior to the national roll-out, it may be useful to focus on the staff with more formal qualifications and highlight to them the value of working under the NQF. It should be noted that participants in this sample had, on average, few formal academic qualifications - with $45 \%$ indicating that their highest level of education was the Irish 
Junior Certificate, which is taken after three years in secondary school. Low levels of formal qualifications may, in turn, affect the ability of the staff to effectively implement the NQF. One potential benefit of the NQF is that the introduction of national standards will allow childcare workers to transfer more easily from centre to centre, thus making ECCEC staff more employable, particularly those staff with fewer formal academic qualifications. In addition, the NQF may provide a counterbalance for the low qualification levels of the staff if implemented with fidelity.

Finally, it is important for centres to examine their organisation style from both a top-down and bottom-up perspective. Clearly, employees desire strong management that will provide help and support during the adaptation phase. On the other hand, authoritarian styles are likely to have a diminishing effect on staff belief in the togetherness and efficacy of the centre. The challenge for ECCECs will be in striking the correct balance between employee independence and guidance.

This study reports some of the first empirical results using the OCRBS (Armenakis et al., 2007) and, therefore, adds to the organisational change knowledge base. The parameters that are crucial for initial support of the NQF have been described in detail and these are, consequently, the crucial building-blocks in the foundation for successful childcare change. It is widely accepted that introducing change to an organisation can cause disruption. Rather than focusing on the outcome of implementing the NQF, the findings from this study give insight into the factors that influence initial support for the change of childcare practice. Readiness for change has been shown to be the "cognitive precursor" to behaviours of resistance or support (Bouckenooghe \& Devos, 2007). Once the NQF has been fully implemented in this pilot community, we will revisit this topic and examine the outcomes associated with the introduction of these changes. Therefore, in future research it will be possible to link readiness for change with the quality standard achieved by each childcare setting.

\section{Notes}

[1] The 12 NQF principles are: The Value of Early Childhood, Children First, Parents, Relationships, Equality, Diversity, Environments, Welfare, Role of the Adult, Teamwork, Pedagogy, and Play.

[2] The skewness and kurtosis test was applied to each measure to test for evidence of normality in all domains. Results indicate that all six domains are non-normal, and therefore nonparametric analyses were used in all tests related to the OCRBS.

[3] Wilcoxon rank sum tests and $t$-tests were applied. The Wilcoxon rank sum test was used for all domains with non-normal distributions (ordering materials, interviewing, training, and planning). The programme objectives domain was normally distributed and therefore a $t$-test was used to identify any significant differences. For each variable, the skewness and kurtosis test was used to determine whether the normality hypothesis should be rejected.

[4] Using the Mann-Whitney test to compare part-time and full-time workers in terms of readiness for change, no statistical differences were found for the discrepancy domain ( $z=0.577, p=0.56)$, the appropriateness domain $(z=0.501, p=0.62)$, the efficacy domain $(z=-0.665, p=0.51)$, the principal support domain $(z=-0.037, p=0.97)$, or the valence domain $(z=1.707, p=0.09)$. 


\section{References}

Andrews, F., \& Withey, S.B. (1976). Social indicators of well-being: Americans' perceptions of quality of life. New York: Plenum Press.

Armenakis, A.A., Harris, S.G., \& Mossholder, K.W. (1993). Creating readiness for organizational change. Human Relations, 46, 681-704.

Armenakis, A.A., Bernerth, J.B., Pitts, J.P., \& Walker, H.J. (2007). Organizational change recipients' beliefs scale: Development of an assessment instrument. Journal of Applied Behavioral Science, 43, 481-505.

Ashford, S.J. (1988). Individual strategies for coping with stress during organizational transitions. Journal of Applied Behavioral Science, 24, 19-36.

Bouckenooghe, D., \& Devos, G. (2007). Psychological change climate as a catalyst of readiness for change: A dominance analysis (Ghent University, Faculty of Economics and Business Administration Working Paper 2007/483). Retrieved from http://www.feb.ugent.be/nl/ Ondz/wp/Papers/wp_07_483.pdf

Cameron, K. (2008). Paradox in positive organizational change. Journal of Applied Behavioral Science, 44, 7-24.

Duignan, M. (2005). Talking about quality: Report of a consultation process on quality in early childhood care and education in Ireland. Child Care in Practice, 11, 211-230.

Gilmore, T.N., \& Barnett, C. (1992). Designing the social architecture of participation in large groups to effect organizational change. Journal of Applied Behavioral Science, 28, 534-548.

Jorde-Bloom, P. (1995). Shared decision making: The centerpiece of participatory management. Young Children, 50, 55-88.

Jorde-Bloom, P. (1996). Improving the quality of work life in the early childhood setting: Resource guide and technical manual for the Early Childhood Work Environment Survey. Wheeling, IL : The Early Childhood Professional Development Project, National Louis University.

Kagan, S.L., \& Neuman, M.J. (1997). Defining and implementing school readiness: Challenges for families, early care and education, and schools. In R.P. Weissberg, T.P. Gullotta, R.L. Hampton, B.A. Ryan, \& G.R. Adams (Eds.), Healthy children 2010: Establishing preventative services (pp. 61-96). Thousand Oaks, CA: Sage Publications.

Kanter, R. (1983). The change masters. New York: Simon and Schuster.

Kotter, J. (1995). Leading change: Why transformation efforts fail. Harvard Business Review, 73(2), 59-67.

Leiter, M.P., \& Harvie, P. (1998). Conditions for staff acceptance of organizational change: Burnout as a mediating construct. Anxiety, Stress and Coping, 11, 1-25.

Martin, A.J., Jones, E.S., \& Callan, V.J. (2005). The role of psychological climate in facilitating employee adjustment during organizational change. European Journal of Work and Organizational Psychology, 14, 263-289.

Munton, A.G., \& Mooney, A. (1999). Improving the quality of childcare provision through selfassessment: Organizational characteristics of nurseries as predictors of the ability to plan and implement change. Early Child Development and Care, 148, 21-34.

Munton, A.G., Mooney, A., \& Rowland, L. (1997). Quality in group and family daycare provision: Evaluating self-assessment as an agent of change. European Early Childhood Education Research Journal, 5(1), 59-76.

National Institute of Child Health and Human Development Early Childcare Research Network. (2000). The relation of child care to cognitive and language development. Child Development, $71,960-980$.

National Institute of Child Health and Human Development Early Childcare Research Network. (2002). Early child care and children's development prior to school entry: Results from the NICHD Study of Early Child Care. American Educational Research Journal, 39, 133-164. 
National Institute of Child Health and Human Development Early Child Care Research Network. (2008). Mothers' and fathers' support for child autonomy and early school achievement. Developmental Psychology, 44, 895-907.

National Institute of Child Health and Human Development Early Child Care Research Network, \& Duncan, G.J. (2003). Modelling the impacts of child care quality on children's preschool cognitive development. Child Development, 74, 1454-1475.

Office of the Minister for Children and Youth Affairs. (2009). General terms and conditions governing participation in the early childhood care and education (ECCE) scheme. Retrieved from http://www.omc.gov.ie/viewdoc.asp?fn =/documents/childcare/ECCE_Scheme_Pack/ Terms_and_Conditions_ECCE_Sept_2010.doc

Peisner-Feinberg, E.S., Burchinal, M., Clifford, R., Culkin, M., Howes, C., Kagan, S.L., \& Yazejian, N. (2001). The relation of preschool child-care quality to children's cognitive and social development trajectories through second grade. Child Development, 72, 1534-1553.

Phillips, D., Howes, C., \& Whitebook, M. (1991). Child care as an adult work environment. Journal of Social Issues, 47(2), 49-70.

Rodd, J. (1994). Leadership in early childhood. Buckingham: Open University Press.

Sagie, A., \& Koslowsky, M. (1994). Organizational attitudes and behaviors as a function of participation in strategic and tactical change decisions: An application of pathgoal theory. Journal of Organizational Behavior, 15, 37-47.

Schweiger, D.L., \& Ivancevich, J.M. (1985). Human resources: The forgotten factor in mergers and acquisitions. Personnel Administrator, 30(11), 47-61.

Shipper, F. (1991). Mastery and frequency of managerial behaviors relative to sub-unit effectiveness. Human Relations, 44, 371-388.

Stephens, C., \& Wilkinson, J.E. (1995). Assessing the quality of provision in community nurseries. Early Child Development and Care, 108, 83-98.

Taylor, G.S., Templeton, G.F., \& Baker, L.T. (2009). Factors influencing the success of organizational learning implementation: A policy facet perspective. International Journal of Management Reviews, 11, 361-380.

Terry, D.J., Callan, V.J., \& Sartori, G. (1996). Employee adjustment to an organizational merger: Stress, coping and intergroup differences. Stress Medicine, 12, 105-122.

Vandell, D.L., Henderson, V.K., \& Wilson, K.S. (1988). A longitudinal study of children with daycare experiences of varying quality. Child Development, 59, 1286-1292.

Walinga, J. (2008). Toward a theory of change readiness: The roles of appraisal, focus, and perceived control. Journal of Applied Behavioral Science, 44, 315-347.

Walsh, G., \& Gardner, J. (2006). Teachers' readiness to embrace the change in early years of schooling: A Northern Ireland perspective. European Early Childhood Education Research Journal, 14(2), 127-114. 